\title{
Deformation-induced austenite grain rotation and transformation in TRIP-assisted steel
}

\author{
G. K. Tirumalasetty ${ }^{1,2 *}$, M.A. van Huis ${ }^{2,3}$, C. Kwakernaak ${ }^{4}$, \\ J. Sietsma ${ }^{4}$, W.G Sloof ${ }^{4}$,H.W. Zandbergen ${ }^{2}$ \\ ${ }^{1}$ Materials innovation institute (M2i), Mekelweg 2, 2628 CD Delft, The Netherlands \\ ${ }^{2}$ Kavli Institute of Nanoscience, Delft University of Technology, \\ Lorentzweg 1, 2628 CJ Delft, The Netherlands \\ ${ }^{3}$ EMAT, University of Antwerp, Groenenborgerlaan 171, 2020 Antwerp, Belgium. \\ ${ }^{4}$ Department of Materials Science and Engineering, Delft University of Technology, \\ Mekelweg 2, 2628 CD Delft, The Netherlands \\ ${ }^{*}$ Corresponding author: \\ Address: Kavli Institute of Nanoscience, \\ Delft University of Technology, \\ Lorentzweg 1, 2628 CJ Delft, \\ The Netherlands \\ Email: g.k.tirumalasetty@tudelft.nl.
}

Tel./ fax: +31 152781536 / +31 152786600 


\section{Abstract}

Uniaxial straining experiments were performed on a rolled and annealed Si-alloyed TRIP (transformation-induced plasticity) steel sheet in order to assess the role of its microstructure on the mechanical stability of austenite grains with respect to martensitic transformation. The transformation behavior of individual metastable austenite grains was studied both at the surface and inside the bulk of the material using electron back-scattered diffraction (EBSD) and X-ray diffraction (XRD) by deforming the samples to different strain levels up to about $20 \%$. A comparison of XRD- and EBSD-results revealed that the retained austenite grains at the surface have a stronger tendency to transform than the austenite grains in the bulk of the material. The deformation-induced changes of individual austenite grains before and after straining were monitored with EBSD. Three different types of austenite grains can be distinguished that have different transformation behaviors: austenite grains at the grain boundaries between ferrite grains, twinned austenite grains, and embedded austenite grains that are completely surrounded by a single ferrite grain. It was found that twinned austenite grains and the austenite grains present at the grain boundaries between larger ferrite grains typically transform first, i.e. are less stable, in contrast to austenite grains that are completely embedded in a larger ferrite grain. In the latter case, straining leads to rotations of the harder austenite grain within the softer ferrite matrix before the austenite transforms into martensite. The analysis suggests that austenite grain rotation behavior is also a significant contributing factor for enhancement of the ductility.

Keywords: Electron-backscattered diffraction (EBSD), X-ray diffraction (XRD), TRIP steel, deformation, grain rotation, phase transformation. 


\section{Introduction}

The reduction in weight and increasing demands of safety in automotive applications are driving the development of advanced high-strength steels. Micro-alloyed steels with a microstructure consisting of different phases are aimed at producing steels of greater strength without much deterioration of its ductility [1-3].

This material, denoted as TRIP (transformation-induced plasticity) steels, exhibits a complex multi-phase microstructure that consists of a ferritic matrix together with grains of bainite, metastable retained austenite and some martensite [4]. The retained austenite grains transform into martensite during deformation and this will delay the onset of necking, leading to higher ductility by means of the TRIP effect [1]. However, the volume fraction of retained austenite does not contribute directly towards plasticity [5]. These results are consistent with the observations by Jacques et al. [6] that low-Si steel with a low initial content of retained austenite $(\sim 3 \%)$ displaying a significant elongation of $\sim 20 \%$. Therefore, for a more precise description of the microstructure-properties relation in TRIP-assisted steels, it is very important to know the microstructural features that influence the transformation behavior of retained austenite grains during deformation. A very accurate microstructural characterization will enable one to optimize the microstructure and mechanical properties of the material.

Understanding the deformation behavior could lead to an improvement of deformative capabilities of these materials. Therefore, several studies were carried out to reveal the deformation behavior of retained austenite in TRIP steels [7-9]. Experimental 
investigations showed that the austenite stability is affected by: (i) the constraining effect from the phases surrounding the retained austenite [10], (ii) the crystallographic orientation of grains with respect to the loading direction [11], (iii) the local carbon concentration in the austenite [12] and (iv) the grain volume of the retained austenite grains [14]. It has also been observed in these steels that the deformation behavior depends on the morphology of two types of retained austenite grains. Granular-type retained austenite grains were found to be less stable and to transform more easily than the lath-type or film-type austenite grains [13].

The present work aims at investigating the transformation behavior of retained austenite grains in TRIP 800 steel upon uniaxial deformation. The microstructural features that influenced the transformation were identified. To this end, a detailed analysis of retained austenite transformation was conducted both at the surface and inside the bulk of material before and after straining using electron back-scatter diffraction (EBSD) and X-ray diffraction (XRD).

\section{Experiments and testing procedures}

TRIP 800 steel sheets with the chemical composition listed in Table 1 were studied in this work. The ultimate tensile strength of this steel is about $800 \mathrm{MPa}$ as shown in Fig 1a. The material was commercially produced on an industrial continuous annealing line employing a re-heat into the two-phase region and arrested cooling with a lowtemperature bainitic isotherm.

Dog-bone samples were prepared by spark erosion keeping the long axis along the rolling direction. The sample dimensions are shown in Figure 1b. To study the 
deformation behavior, EBSD and XRD experiments were performed on electropolished samples. Prior to electropolishing, the sample surface was ground using SiC emery paper starting with a 350 grain and finishing with a 4000 grain. Then, the electropolishing was performed with freshly prepared electrolyte with a composition of $100 \mathrm{ml}$ perchloric acid and $300 \mathrm{ml}$ butanol in $500 \mathrm{ml}$ methanol at $20 \mathrm{~V}$ and $10{ }^{\circ} \mathrm{C}$ for 20 seconds. Next, the electropolished samples were marked as shown in Figure 1b with small Vickers indentations with an applied load of $0.49 \mathrm{~N}$ to serve as reference points of EBSD patterns and also to determine the local strain of the sample. The indentations were made $1000 \mu \mathrm{m}$ apart and EBSD mapping was performed midway between the indentations to avoid their respective deformation zones. To avoid strain-aging effects and also to prevent carbon contamination of the sample surface, each sample was deformed only once to a desired level of strain. Of each sample, two EBSD maps (indicated as Area 1 and Area 2) and one X-ray diffractogram were recorded before and after deformation. A total of 15 samples were tested during this study.

Orientation imaging microscopy was performed using a JEOL JSM 6500F Schottky field emission gun scanning electron microscope (FEG-SEM) equipped with an HKL Nordlys II detector operated with Channel 5 software. A 20-keV focused electron beam with a beam current of approximately $1 \mathrm{nA}$ was applied. The normal of the sample surface at a working distance of $25 \mathrm{~mm}$ was tilted to $70^{\circ}$ with respect to the electron beam towards the EBSD detector. The distinction between the austenitic face centered cubic (fcc) and ferritic body centered cubic (bcc) phases was straightforward when 9 Kikuchi bands were used to analyze the diffraction patterns. All maps were recorded on areas of $24 \times 18 \mu \mathrm{m}^{2}$ with a step size of $100 \mathrm{~nm}$. The ellipsoid beam spot size was estimated to be $10 \times 25 \mathrm{~nm}^{2}$. From the Kikuchi patterns, the corresponding 
orientation of each crystal lattice was determined with the Channel 5 software from HKL technology developed by Oxford Scientific Instruments.

The XRD measurements were performed on a Bruker D8 Advance diffractometer equipped with a Vantec position-sensitive detector and a graphite monochromator. Data was collected at room temperature using monochromatic Co $\mathrm{K} \alpha$ radiation $(\lambda=$ $0.179026 \mathrm{~nm}), 45 \mathrm{kV}, 35 \mathrm{~mA}$, in the $2 \theta$ region between $30^{\circ}$ and $135^{\circ}$. The step size is $0.034^{\circ}(2 \theta)$ and the counting time per step is 10 seconds. The sample was placed on a Si $\{510\}$ substrate and was not rotated during the measurements. The irradiated area on the sample surface is about $10 \mathrm{~mm}$ in tensile direction or rolling direction and varies in width from 1 to $2 \mathrm{~mm}$ in the normal direction of the sample. XRD diffraction patterns were analyzed using the Bruker program EVA. The austenite fraction is determined from the ratio of the austenite $(\gamma)$ and ferrite $(\alpha)$ diffraction peak intensities as explained by the Jatczak model [15]. The dislocation density in the ferrite phase $(\rho)$ was calculated from the integral breadth of $\{110\},\{200\}$, and $\{211\}_{\alpha}$ peaks as proposed by Vermeulen et al. [16] using the following equation.

$$
\mathrm{BS}_{\mathrm{S}}^{*}=\mathrm{k}^{*} \mathrm{~g}^{*} \mathrm{v}^{*} \rho
$$

Here $b^{*}$ represents the length of Burgers vector (recommended value $0.866 * a$ for ferrite). $g^{*}$ is the length of reciprocal diffraction vector given by $\frac{\sqrt{h^{2}+k^{2}+l^{2}}}{a}$, while $\mathrm{k}^{*}$ is a dimensionless coefficient associated with dislocation distribution, the orientation of dislocations with respect to the diffraction vector and is taken as 1 during the calculation. $\mathrm{Bs}^{*}$ is the integral breadth in the reciprocal space and is calculated from the real space breadth (Bs) through $\mathrm{Bs}^{*}=\frac{\mathrm{Bs} \cos \theta}{\lambda}$ where $\lambda$ is the wavelength of the X-ray beam and Bs is in radians. The integral breadth (Bs) is 
calculated from $\mathrm{Bs}^{3 / 2}=\mathrm{Bm}^{3 / 2}-\mathrm{Bi}^{3 / 2}$ where $\mathrm{Bm}$ is the measured breadth of the ferrite peaks and $\mathrm{Bi}$ is the contribution of the instrument to the total peak width. In this case, $\mathrm{Bi}$ is calculated from the instrumental peak width of $\mathrm{LaB}_{6}$ powder.

The experimental stress-strain curve of the investigated steel is shown in Figure 1a. The rectangular gauge section of the specimen had dimensions of $20 \times 5 \times 1 \mathrm{~mm}^{3}$. The tensile testing experiments were performed with a $5 \mathrm{kN}$ Deben Microtest tensile stage, which was controlled by dedicated Microtest software from Deben. The tensile tests were executed with a constant deformation rate of $1.2 \times 10^{-3} \mathrm{~s}^{-1}$. The stress-strain response for each of the samples used for XRD and EBSD analysis are indicated in Figure 1a. The stress-strain curve represents the bulk deformation behavior of the sample and but showed higher values of strain $(\sim 2-2.5 \%$ more than the local permanent strain) due to machine compliance. The local permanent strain experienced by the samples was therefore considered by measuring the distance between the indentations as shown in Figure $1 \mathrm{~b}$ before and after the tensile test.

Optical microscopy (OM) was also used for the microstructural examination. A coloretching procedure as proposed by De et al. [17] was used to reveal the different phases.

\section{Results and discussions}

3.1 Characterization of retained austenite grains at the surface and inside the bulk of the steel before and after deformation

Light microscopic observations were performed in order to assess the deformation behavior near the surface and along the cross sections of the samples. The color- 
etching technique revealed ferrite in an off-white color, austenite in white and martensite in a straw tint and dark colour [17]. The retained austenite was distinguishable from ferrite and martensite and, consequently, the retained austenite phase fractions of microstructures shown in Figure 2 were measured using an Image analyser. The analysis of Figures 2a, 2c and 2e before deformation resulted in austenite area fractions of $8.4 \pm 2.5 \%, 10.4 \pm 3.2 \%$ and $13 \pm 3.7 \%$. The mean and the standard deviation are estimated by performing 4 individual different measurements on the same area of each figure, thereby varying the criteria for the color recognition. The differnces in austenite fraction in Figures 2a, 2c and 2e could be due to the rolling microstructure, which is anisotropic. The samples were deformed to $12.5 \%$ strain and the examination of samples after deformation revealed that the fraction of retained austenite near the surface $(0.05 \%$ along the TD-RD plane, Figure $2 \mathrm{~b})$ was considerably lower than in the cross sections $(2.5 \pm 0.7 \%$ along the ND-TD plane, Figure $2 \mathrm{~d}$, and $3.9 \pm 1.2 \%$ along the ND-RD plane, Figure $2 \mathrm{f}$ ).

As the Image analyzer is has limited accuracy, EBSD and XRD measurements were performed in order to understand the differences in the deformation behavior of retained austenite grains both at the surface and inside the bulk of the material. Initially XRD measurements were taken on a set of four samples that were not deformed. The average retained austenite fraction for four measurements in Table 2 is $17.4 \pm 0.4 \%$. Similar XRD measurements were taken after deformation. The retained austenite fraction was found to decrease with strain as observed in Figure 3; the corresponding values are listed in Table 2. Retained austenite and ferrite can easily be distinguished by EBSD as they have different crystallographic structures whereas grains of martensite, grain boundaries and areas with a high dislocation density are 
not indexed by the software due to the poor strength of the Kikuchi patterns. Table 3 shows that the absolute fractions of retained austenite determined with EBSD vary from one sample to another and from one area to another. This variation in retained austenite demonstrates the inhomogeneous distribution of retained austenite grains within the steel as can be seen in Figure 4. The absolute fractions are more consistent when using XRD because a considerably larger area of the sample is probed. Furthermore, the analysis depth with XRD is about $11 \mu \mathrm{m}$, which is considerably larger than the analysis depth of diffracted electrons, which is maximal $50 \mathrm{~nm}$.

The relative changes in retained austenite were used to describe the effect of strain as observed with both EBSD and XRD before and after deformation. As a result, the calculated relative fractions agree with data sets in Table 3 for the EBSD maps corresponding to Area 1 and Area 2. Figure 3 shows the relative variation of retained austenite determined with XRD and EBSD, respectively. Matsumura et al. [18] suggested that relative fractions of retained austenite $\left(\mathrm{F}^{\gamma}\right)$ will decrease with increasing strain $(\varepsilon)$. The decay follows an inverse relationship in which A and B were fitted with a least squares method:

$$
\mathrm{F}^{\gamma}=\frac{1}{\{A \times \varepsilon+B\}}
$$

where $\mathrm{A}=0.1295$ and $\mathrm{B}=0.9734$ for the $\mathrm{XRD}$ data set, whereas $\mathrm{A}=0.2800$ and $\mathrm{B}=$ 0.9339 for the EBSD data sets. The sum of the squares of the residuals for the XRD fit was found to be 0.0081 and for EBSD fit to be 0.0811 . The stronger decrease in the relative trend of the retained austenite fraction of EBSD compared with that of XRD is explained by the differences in penetration depths with EBSD and XRD. These results are consistent with light microscopic observations that retained austenite grains near the surface transformed faster than in the bulk of the sample. These differences 
in transformation behavior could be due to the spatial freedom for austenite grains at the surface. Considering the shape changes associated with the austenite-to-martensite transformation, the grains at the surface are less spatially constrained than the grains in the bulk, allowing the transformation to proceed more easily at the surface. Therefore, during the tensile test the austenite grains at the surface tend to transform at lower strains than the grains inside the bulk. This possibly accounts for the observed differences in the transformation behaviors at the surface and along the cross-sectional planes of these materials. The difference between XRD and EBSD data in Figure 3 could also be due to the limited area of the analysed EBSD maps, which cannot directly provide statistical information about the bulk. The EBSD investigations are nonetheless very valuable for revealing new insights into the deformation/transformation behaviors which can significantly extend our knowledge of these materials.

\subsection{Micro-mechanical behavior of retained austenite grains during deformation}

The deformation behavior of individual austenite grains at different strains was further investigated with the help of phase identification maps, inverse pole figure maps, Schmid factor maps, and band contrast maps as shown in Figures 4-6, S1 and S2 in the supporting information. The band contrast maps are used to distinguish ferrite and austenite grains from martensite grains. Martensite grains usually show a poor band contrast because of their high dislocation density. Phase identification maps are used to display the ferrite and austenite phases and to determine their fractions. The inverse pole figure maps are used to analyze the grain orientations. The corresponding color coding is given as a function of orientation with respect to the rolling direction. The rolling (RD), transverse (TD) and normal (ND) directions of the 
specimen were taken as the specimen coordinate system in the crystallographic orientation analysis. The tensile direction corresponds to RD in this study. The Schmid factor is a measure of the relative ease with which each grain slips. In fcc metals, it is well known that dislocation movement occurs in four $\{111\}$ slip planes with three possible <110> slip directions. Hence, 12 possible slip systems were considered for austenite. The grains having a higher Schmid factor are indicated in red whereas those with a very low Schmid factor are indicated in blue using rainbow coloring.

The microstructural changes and the transformation behavior of three types of austenite grains were carefully analyzed before and after deformation during this study. The first type of austenite grains were positioned at the ferrite triple edges. The second type contained twin faults, and the third type was completely embedded in a single ferrite grain.

Austenite grains at ferrite triple junctions

Upon deformation to $1.1 \%$ strain in Figure 4b, the TRIP 800 samples showed a transformation of some retained austenite grains. These austenite grains were mainly observed between the ferrite grains at the triple junctions as shown in the phase identification maps. When the samples are strained to 5.3\%, it can be seen that 6 out of 10 such austenite grains at the ferrite grain boundaries have transformed in comparison to the $1.1 \%$ strain case where 4 out of 14 austenite grains have transformed, as shown in Figure 4d. With a further increase of the strain to 9.6\% (Figure 4f), it can be seen that the majority (12 out of 15) of retained austenite grains at the ferrite triple junctions have transformed. Upon straining to $13.4 \%$ the samples 
show complete transformation of all the austenite grains at the ferrite grain boundaries as shown in Figure 4h.

The early transformation of austenite grains at the triple junctions could be attributed to the higher localized stresses at the grain boundaries. As the orientation of ferrite grains is different from that of its neighboring grains, each of these grains tends to deform differently resulting in higher stresses at the grain boundaries. In the general case, this will result in a triaxial state of stress on the grains of austenite and these are apparently more likely to transform during the deformation as suggested by Shan et al. [19]. In principle, apart from triple junctions, austenite grains can also be present at quadruple junctions within these steels. Although it is difficult to observe these with the EBSD maps, the transformation behavior of austenite grains at these junctions is expected to be similar to that of triple junctions.

\section{Twinned austenite grains}

Annealing twins are often seen in fcc metals as a result of cold working followed by annealing heat treatment [20]. However, the stability of fcc austenite grains with twin faults during the deformation process is yet not fully understood. Therefore the deformation behavior of twinned austenite grains was also carefully assessed during this work. The austenite grains having twin faults were distinguished from other austenite grains with the help of Special Boundaries (SB) in the HKL software by using an axis-angle definition to identify these boundaries. These twinned crystals were described by a $60^{\circ}$ rotation about $<111>$ between neighboring austenite grains and were indicated with blue boundaries in the phase identification maps in Figures 4a-4h. The samples strained to $1.1 \%$ showed that three of the twinned grains have 
transformed completely, whereas two of them have undergone a partial transformation as seen in Figure $4 \mathrm{~b}$. When the samples are strained to 5.3\%, the majority (4 out of 6 ) of these twinned austenite grains have been transformed, as is clear from the phase identification maps in Figure 4d. With a further increase of the strain to $9.6 \%$ (Figure $4 \mathrm{f}$ ) and $13.4 \%$ (Figure $4 \mathrm{~g}$ ) it is observed that all the twinned austenite grains have been completely transformed. From these observations it is clear that the local defects such as twins lower the stability of austenite grains and lead to an early transformation during the deformation process.

The possibility of martensitic transformation with twinning faults can be explained from the theory proposed by Hendrick and Schockley [21]. According to this theory, it is energetically feasible for twinning dislocation in fcc materials having a Burgers vector of $\frac{a}{2}[10 \overline{1}]$ to split into two partial dislocations, resulting in a nearly bcc (martensite) crystal structure. This dislocation reaction can be written as:

$$
\frac{a}{2}[10 \overline{1}] \rightarrow \frac{a}{6}\left[\begin{array}{lll}
2 & \overline{1} & \overline{1}
\end{array}\right]+\frac{a}{6}[11 \overline{2}]
$$

Similar to the austenite grains at the ferrite triple junctions, the surroundings do influence these twinned austenite grains. Figure S1c shows an austenite grain with twins $\mathrm{T} 1$ and $\mathrm{T} 2$. Observations after deformation of $1.1 \%$ strain revealed that twin $\mathrm{T} 1$ has completely transformed, whereas twin T2 has undergone a partial transformation with a change in orientation as seen in Figure S1d. In this case, both these twins T1 and T2 were seen to react differently due to the inherent differences in their orientations. The orientation changes after deformation in Figure S1d suggest that during the deformation each of these twins rotate differently, which generates higher 
stress at the twin boundary and thereby induces the transformation. Hence, these grains are observed to transform during the earlier stages of the deformation.

\section{Austenite grains embedded in single ferrite grains}

Further careful examination of all the strained samples revealed that the retained austenite grains within the ferrite grains have undergone rotations. The inverse pole figure maps in Figure 5b showed that 13 out of 18 retained austenite grains embedded inside ferrite grains (indicated within the black squares) have changed their orientation after the deformation. The samples upon further straining to $5.3 \%$ (Figure 5d) showed that 10 out of 15 such grains have undergone rotations. Although some of these rotations could not be seen clearly in the inverse pole figure maps, one can verify the grain rotations from the changes in contrast of Kikuchi patterns in band contrast maps (Figure S2). As the grain rotation leads to a change in the orientation of slip planes and slip directions, the changes in the Schmid factor maps in Figures 6a-6h can also serve to indicate the rotation of these austenite grains. With a further increase in strain to $9.6 \%$, it is clear from Figure $5 \mathrm{f}$ and Figure $6 \mathrm{f}$ that 4 out of 7 untransformed embedded austenite grains change their orientations. Changes can be seen clearly from both the band contrast maps and from the Schmid factor map, indicating that these grains have rotated. When the material is deformed at $13.4 \%$ strain (Figure $5 \mathrm{~h}$ and Figure 6h), all the grains have transformed except for two embedded austenite grains, which underwent a partial transformation with a change in their orientations.

In order to quantify the grain rotations, the angle and the axis of rotation was calculated for the above-mentioned embedded austenite grains (numbered in the band contrast maps in Figure S1a and Figures S2a,c,e,g) and the surrounding ferrite grains. 
The axis and the angles of these grains were calculated from Bunge notation as mentioned in Ref. [22] before and after deformation from the changes in Euler angles as shown in Table S1. The relative grain rotation of austenite grains numbered 7-12 with $1.1 \%$ strain was investigated. All these austenite grains were chosen within a single ferrite grain as seen in Figure S2a. These grains resulted in rotation angles of $3.9^{\circ}, 4.7^{\circ}, 3.9^{\circ}, 8.4^{\circ}, 9.3^{\circ}$ and $1.5^{\circ}$ respectively. Interestingly, grains 10 and 11 , which possessed similar orientations (see Figure 5a), have rotated by similar angles of $8.4^{\circ}$ and $9.3^{\circ}$, respectively. These observations are also consistent with grains 2 and 4 in Figure S1 a, which show rotation angles of $8.1^{\circ}, 6.4^{\circ}$ and with grains $4-7$ in Figure S2c, which show rotation angles of $2.8^{\circ}, 3.1^{\circ}, 1.5^{\circ}$ and $3.8^{\circ}$ respectively. The above results demonstrate that grains having a similar crystallographic orientation with respect to the straining direction experience similar rotations.

The local deformation and transformation behavior of these embedded austenite grains is further assessed with the help of Schmid factor maps. It is well known that grains having the highest Schmid factor will undergo deformation faster because the slip planes in these grains need not undergo much rotation before the resolved shear stress reaches a critical value. However, in this steel we observed that 16 out of 21 investigated embedded austenite grains with the highest Schmid factors (indicated in red in Figure 6) did not transform to martensite, but rotated instead. The changes in the Schmid factor was further investigated for 40 embedded grains with both higher and lower Schmid factors before and after deformation. The analysis revealed that 31 of these grains have a lower Schmid factor after deformation. A plot of the Schmid factor as a function of strain for all these grains is shown in Figure 7. The plot clearly shows a decrease in the Schmid factor with increasing strain. As the tensile axis is 
fixed during the deformation, the slip planes and slip directions will rotate due to grain rotation. Given that the Schmid factor is the ratio of resolved shear stress to axial stress, a lowering of the Schmid factors would result in a lowering of critical resolved shear stress for martensitic transformation. Thereby these embedded austenite grains are found to transform at later stages of deformation.

From the observations discussed above, the question now arises why the austenite grains often rotate prior to the transformation to martensite. First, a distinction should be made between austenite grains at triple junctions and austenite grains that are completely embedded by a single, larger ferrite grain. Rotations were observed only in the case of the "embedded" austenite grains as seen in Table S1. The rotations are caused by strain and they occur preferentially within single ferrite grains because the stress state around the embedded austenite grains is much more uniform than the austenite grains at the ferrite triple junctions. Therefore a high local stress, which could act as a driving force for the transformation, is not easily obtained. Hence, rather than to undergo a phase transformation, the austenite crystal rotates, most likely because the stress can be better accommodated along particular crystallographic directions. These grains of retained austenite within the ferrite grain transform at a later stage because these hard austenite grains can respond to the stresses exerted on them by the surrounding ferrite grains by undergoing rotations in a soft ferrite matrix.

\subsection{Grain rotation-induced plasticity}

Dislocation densities inside ferrite grains were calculated from analysis of the width of XRD-peaks (see Section 2, figure 8a) as a function of strain to understand the deformation behavior in these steels. Considering the anisotropy in this multi-phase 
steel, the dislocation density was calculated for $\{110\},\{200\}$, and $\{211\}$ family of planes for ferrite. It was observed that the dislocation density in ferrite increases with increasing strain as can be seen in Figure 8b. The increased dislocation density in ferrite and the decreased austenite content presented in Figure 3 after $13.4 \%$ and 19.2\% strain indicate that ferrite starts to take up the majority of the nominal strain after 13.4\%. However, according to Bhadeshia [5], the austenite-to-martensite transformation contributes only $\sim 2 \%$ of the total strain. Therefore the question remains as to which mechanism contributes to the ductility during the initial $10 \%$ of strain.

Recent findings by Liu et al. [23] indicate that grain rotations during the tensile test are a potential source of ductility in nanocrystalline metals. Moreover, molecular dynamics simulations by Haslam et al. [24] suggest that elastic anisotropy of surrounding grains may well contribute to grain rotations in polycrystals with grain sizes greater than $1 \mu \mathrm{m}$. Therefore, austenite grain rotations were closely assessed to understand the plastic deformation behavior in these materials.

The contribution of grain rotations to the ductility can be understood by considering the austenite grain labeled A as shown in Figures S1c and S1d. The austenite grain is clearly seen to have undergone a physical rotation, leading to a change in the crystallographic orientation. Changes in the austenite grain shapes were considered from the EBSD maps in Figure S2a. The shape of austenite grain 7 can be treated approximately as an ellipsoid with its long axis nearly perpendicular to the loading axis. With the increasing external strain seen in Figure S2b, the short axis of the grain increases gradually and the long axis decreases. The increased dislocation density in 
the surrounding ferrite grains indicates that the plasticity was accommodated in ferrite grains by the grain reshaping process during these rotations. Most likely upon deformation the austenite grains rotate through a combined mechanism of grain boundary slip and grain boundary migration as discussed by Haslam et al. [24]. As most of the austenite grains are non-spherical in shape, this will result in a change in length along the tensile direction, i.e., the rotation of the harder austenite grain within the softer ferrite can contribute to tensile extension. Furthermore, it is well known that strain hardening is caused by dislocation pileups at the barriers in a crystal [21]. The rotation of embedded austenite grains, which acts as a barrier to the movement of dislocations inside ferrite grains, could reduce the back stress on dislocations and postpone the crack initiation process. This can result in the delay of necking during the tensile deformation, thereby leading to an enhanced ductility in these steels. The specific rotation of a particular embedded austenite grain will depend both on the local stress state and the relative orientation of the austenite and ferrite grains. Grains at the surface (as probed by SEM and EBSD) are less confined than grains in the bulk. Therefore, surface grains are more susceptible to shape changes and reorientations. Recent investigations by Jang and Greer [25] suggest that the presence of free surfaces activates grain boundary mediated processes like grain rotations due to the reduction in sample dimensions during the deformation process. Nonetheless, it can be expected that these processes also occur in the bulk, which has been previously observed for bulk grains in aluminum during deformation [26]. Considering that the ferritic matrix is soft and the grains of austenite are hard, such rotations are also feasible in the bulk of the steel. However, rotations in the bulk will likely be less pronounced than the ones observed at the surface. Micromechanical modeling 
simulations of strain-induced austenite grain rotations within single ferrite grains may be an interesting topic of research for future work.

\section{Conclusions}

The deformation behavior of TRIP 800 steel sheet was investigated at the surface and inside the bulk by performing EBSD and XRD experiments. These experiments show that the retained austenite grains at the surface have a stronger tendency to transform than the retained austenite grains in the bulk of the material. Local defects, such as twins, lower the stability of austenite grains and thus transform at the earlier stages during the deformation process. Austenite grains positioned at grain boundaries between multiple ferrite grains were amongst the first to transform, whereas austenite grains that are completely embedded in larger ferrite grains were often found to undergo rotations. These differences in strain-induced behavior are likely associated with different stress states and grain rotation capabilities experienced by the austenite grains upon deformation. The rotation angles of embedded austenite grains were found to be dependent on the crystallographic orientation of the grains with respect to the straining direction. A lowering of Schmid factors of embedded austenite grains is seen to be the driving force for the delayed transformation of these grains during the deformation process. The current findings suggest that grain rotation is an additional mechanism contributing to the high ductility of these steels and may be as important as the contribution of the austenite-martensite transformation.

\section{Acknowledgements}

This research was carried out under project number MC5.06280a of the Materials innovation institute M2i (www.m2i.nl). The authors thank G. Hoveling, E. Peekstok and V. Svechnikov for the EBSD sample preparation. The authors are furthermore 
grateful to R.W.A. Hendrikx for his help with the XRD analysis and to S.P. Kuniewski for mathematical analysis and for useful discussions. The authors also take pleasure in thanking Dr. D.N. Hanlon (Tata Steel RDT) for providing the material for this study and for his fruitful discussions.

\section{References}

[1] Zackay VF, Parker ER, Fahr D, Bush R. Trans. ASM 1967; 60: 252-259.

[2] Sugimoto K, Kobayashi M, Hashimoto S, Metall. Trans 1992; 23A: 3085.

[3] Jacques PJ, Ladrie`re J, Delannay F, Metall. Mater. Trans. A 2001; 32: 27592768.

[4] Girault E, Martens A, Jacques P, Houbaert Y, Verlinden B, Van Humbeeck J. Scripta Mater 2001; 44: 885.

[5] Bhadeshia HKDH. ISIJ Int 2002; 42: 1059-1060.

[6] Jacques PJ, Girault E, Mertens A, Verlinden B, Van Humbeeck J, Delannay F, ISIJ Int. 2001; 41 (9): 1068-1074.

[7] Tomota Y, Tokuda H, Adachi Y, Wakita M, Moriai A, Morii Y. Acta Mater 2004; 52: 5737-45.

[8] Jacques PJ, Furnémont Q, Lani F, Pardoen T, Delannay F. Acta Mater 2007; 55: 3681-3693.

[9] Petrov R, Kestens L, Wasilkowska A, Houbaert Y. Materials Science and Engineering A 2007; 447: 285-297.

[10] Timokhina IB, Hodgson PD, Pereloma EV. Metall. Mater. Trans. A 2003; 34: 1599-1609.

[11] Kruijver SO, Zhao L, Sietsma J, Offerman SE, van Dijk NH, Lauridsen EM, Margulies L, Grigull S, Poulsen HF, van der Zwaag S, J. Phys. IV 2003; 104: 499-502.

[12] van Dijk NH, Butt AM, Zhao L, Sietsma J, Offerman SE, Wright JP, van der Zwaag S, Acta Mater 2005; 53: 5439-5447.

[13] Park KK, Oh ST, Baeck SM, Kim DI, Han JH, Han HN. Park. Materials Science Forum 2002; 408-412: 571-576.

[14] Jimenez-Melero E, van Dijk NH, Zhao L, Sietsma J, Offerman SE, Wrightc JP. Scripta Mater 2007; 56: 421. 
[15] Jatczak CF, Larson JA, Shin SW. Society of Automotive Engineers, Warrendale, PA; 1980.

[16] Vermeulen AC, Delhez R, De Keijser ThH, Mittemeijer EJ. Journal of Applied Physics 1995; 77: 5026-5049.

[17] De AK, Speer JG, Matlock DK. Adv. Mater Proc 2003; 161: 27-30.

[18] Matsumura O, Sakuma Y, Takechi H. Scripta Metallurgica, 1987; 21: 13011306.

[19] Shan TK, Li SH, Zhang WG, Xu ZG. Materials and Design 2008; 29: 1810 1816.

[20] Kelly A, Groves GW, Kidd P. Crystallography and crystal defects, first ed., London: Longman; 1973.

[21] Dieter GE, Mechanical Metallurgy, third ed., New York: McGraw-Hill; 1988.

[22] Engler O, Randle V. Introduction to Texture Analysis: Macrotexture, Microtexture, and Orientation Mapping, first ed., CRC Press; 2000; pp: 26-34.

[23] Liu P, Mao SC, Wang LH, Han XD, Zhang Z. Scripta Mater 2011; 64: 343346.

[24] Haslam AJ, Moldovan D, Yamakov V, Wolf D, Philpot SR, Gleiter H, Acta Mater 2003; 51: 2097.

[25] Jang D, Greer JR, Scripta Mater 2011; 64: 77-80.

[26] Margulies L, Winther G, Poulsen HF, Science 2001; 291 (5512): 2392-2394. 


\section{Tables}

Table 1: Chemical composition (wt.\%) of TRIP 800 steels

\begin{tabular}{ccccccccc}
\hline $\mathbf{C}$ & $\mathbf{M n}$ & $\mathbf{S i}$ & $\mathbf{A l}$ & $\mathbf{C r}$ & $\mathbf{N i}$ & $\mathbf{C u}$ & $\mathbf{P}$ & $\mathbf{S}$ \\
\hline 0.199 & 1.650 & 1.530 & 0.037 & 0.026 & 0.024 & 0.014 & 0.011 & 0.004 \\
\hline
\end{tabular}

Table 2: XRD analysis of retained austenite content in TRIP 800

\begin{tabular}{cccc}
\hline Strain (\%) & $\begin{array}{c}\text { XRD fraction of } \\
\text { retained austenite } \\
\text { (absolute) [\%] }\end{array}$ & $\begin{array}{c}\text { Std dev due to } \\
\text { counting } \\
\text { statistics [\%] }\end{array}$ & $\begin{array}{c}\text { XRD fraction of } \\
\text { retained austenite } \\
\text { (relative) }\end{array}$ \\
\hline 0 & 17.1 & 0.5 & 1 \\
0 & 17.1 & 0.6 & 1 \\
0 & 17.8 & 0.4 & 1 \\
0 & 17.6 & 0.3 & 1 \\
1.1 & 16.3 & 0.7 & 0.9 \\
2.8 & 12.8 & 0.5 & 0.7 \\
5.3 & 9.5 & 0.4 & 0.5 \\
9.6 & 8.1 & 0.3 & 0.4 \\
13.4 & 6 & 0.2 & 0.3 \\
19.2 & 5.6 & 0.2 & 0.3 \\
\hline
\end{tabular}

Table 3: EBSD analysis of retained austenite contents in TRIP 800

\begin{tabular}{ccccc}
\hline $\begin{array}{c}\text { Strain } \\
\text { (\%) }\end{array}$ & $\begin{array}{c}\text { EBSD fraction } \\
\text { of retained } \\
\text { austenite } \\
\text { (absolute) }\end{array}$ & $\begin{array}{c}\text { EBS] } \\
\text { of retained } \\
\text { austenite } \\
\text { (relative) }\end{array}$ & $\begin{array}{c}\text { Area 2 } \\
\text { EBSD fraction } \\
\text { of retained } \\
\text { austenite } \\
\text { (absolute) [\%] }\end{array}$ & $\begin{array}{c}\text { EBSD fraction } \\
\text { of retained } \\
\text { austenite } \\
\text { (relative) }\end{array}$ \\
\hline 0 & 10.9 & & 16 & \\
1.1 & 8 & 0.7 & 13.2 & 0.8 \\
0 & 9.5 & & 10.7 & \\
5.3 & 5.4 & 0.6 & 5.5 & 0.5 \\
0 & 4.2 & & 10.7 & 0.3 \\
9.6 & 1.2 & 0.3 & 2.9 & \\
0 & 10.6 & & 12.5 & 0.1 \\
13.4 & 1.8 & 0.2 & 0.5 & 0.1 \\
0 & 11.7 & & 8.6 & \\
19.2 & 0.8 & 0.1 & 1.1 & \\
\hline
\end{tabular}


Figure 1
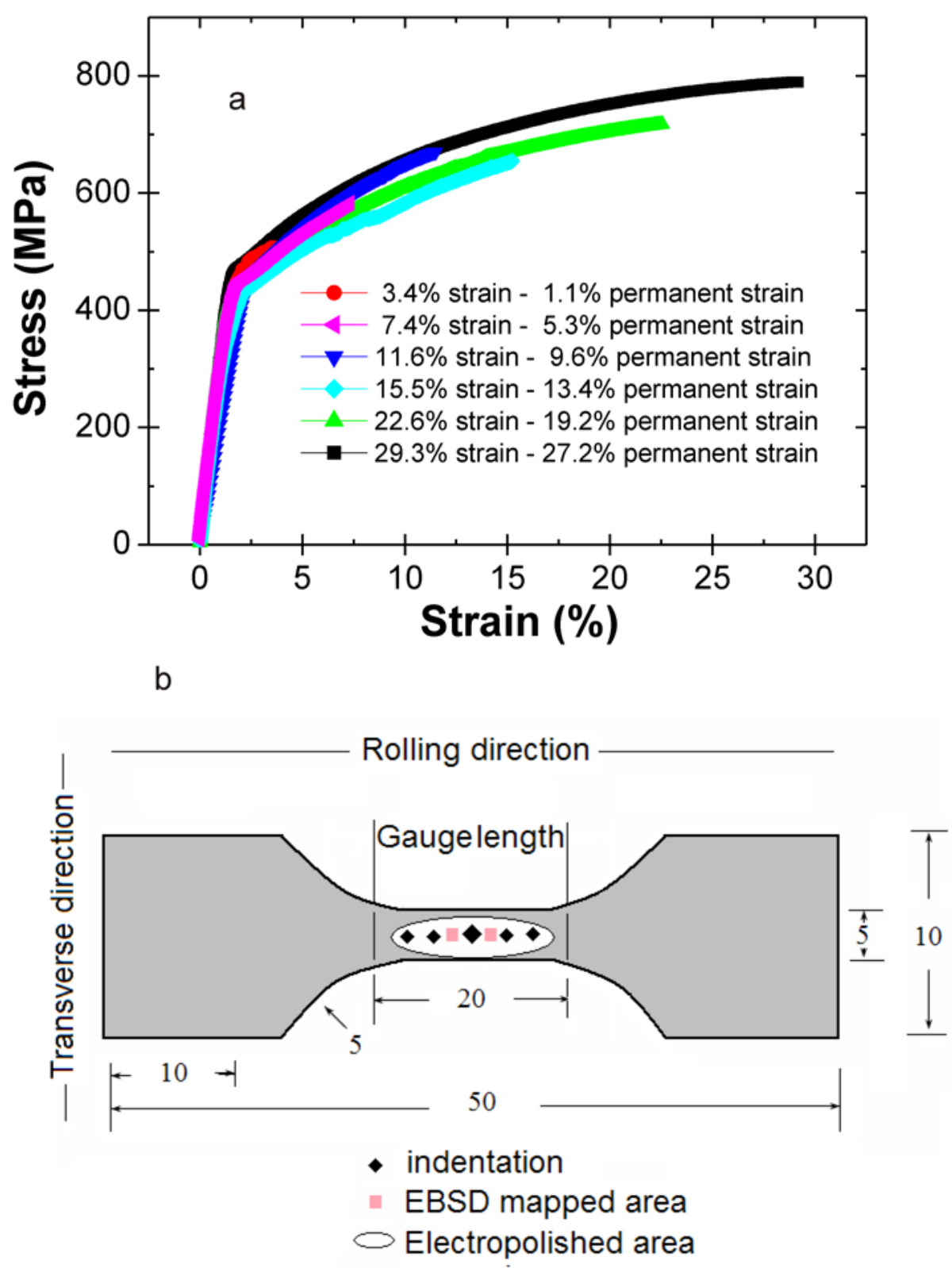

Fig 1: a) Stress-strain responses of various TRIP 800 samples in tension. For the sake of easy distinction, the plots with $13.4 \%$ and $19.2 \%$ permanent strain were shifted below the plot with $27.2 \%$ strain by 40 and $60 \mathrm{MPa}$, respectively. b) The geometry of the samples used for the EBSD and XRD measurements (dimensions are in millimeters). 
Figure 2

Before deformation
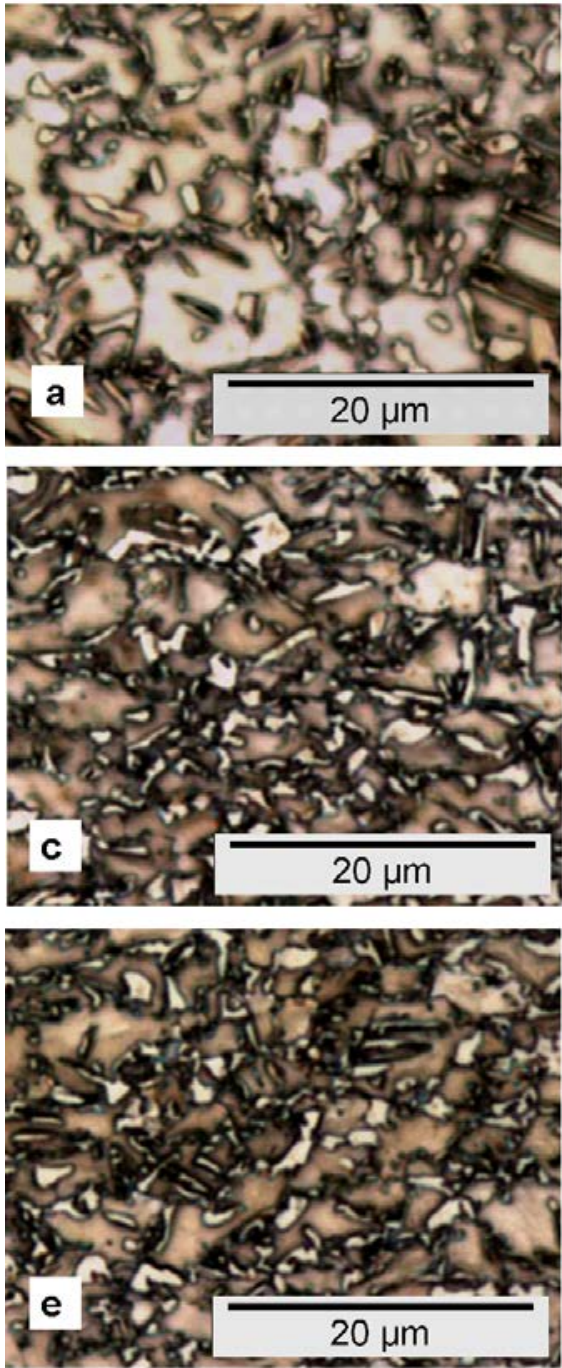

After deformation

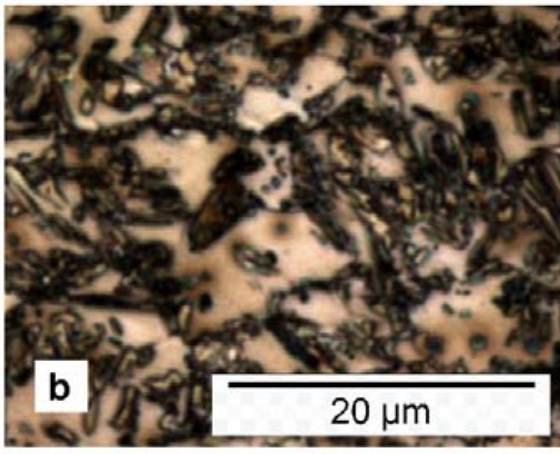

TD
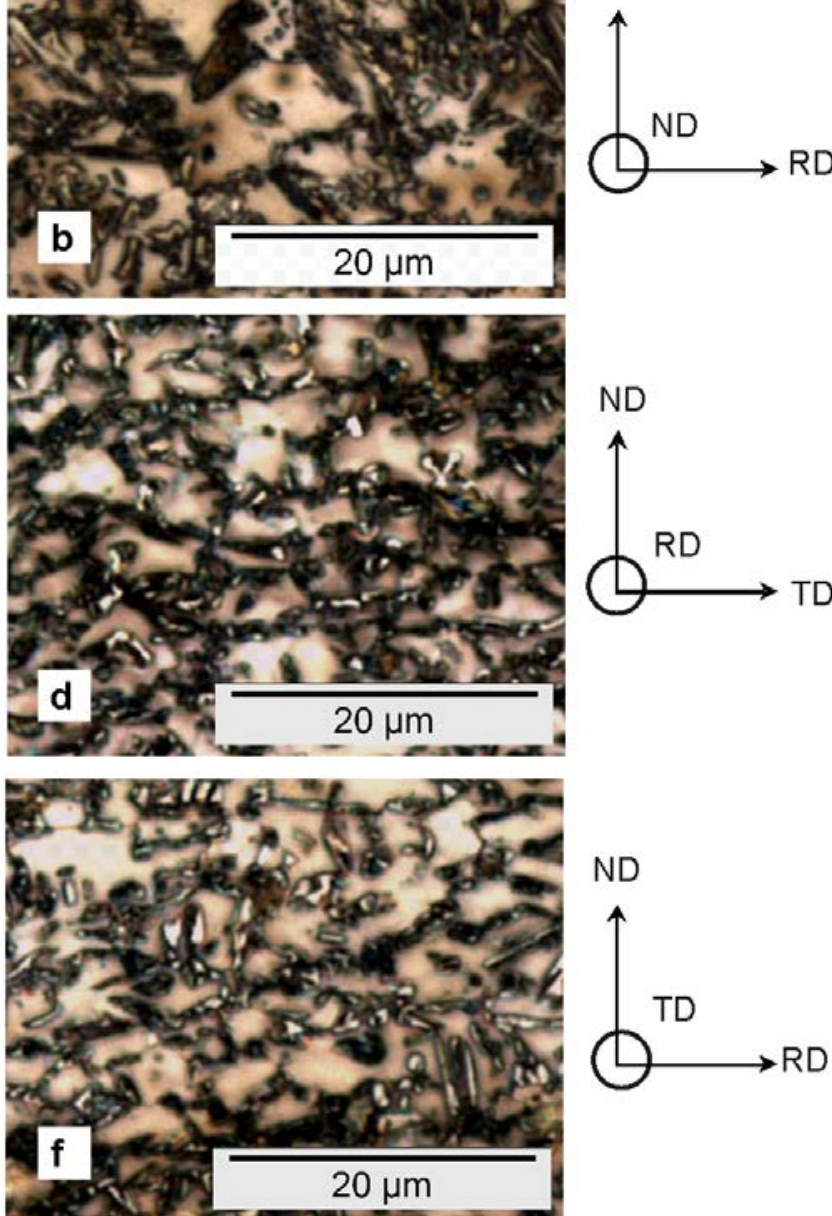

ND

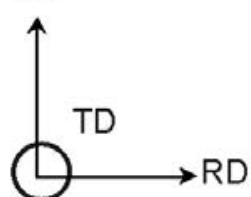

Fig 2: Light microscopic analysis and variation of retained austenite with $12.5 \%$ strain. Ferrite grains are etched in an off-white color while austenite grains are seen in white and martensite grains are in straw tint and dark colour. (TD-Transverse Direction, ND-Normal Direction, RD-Rolling Direction). 
Figure 3

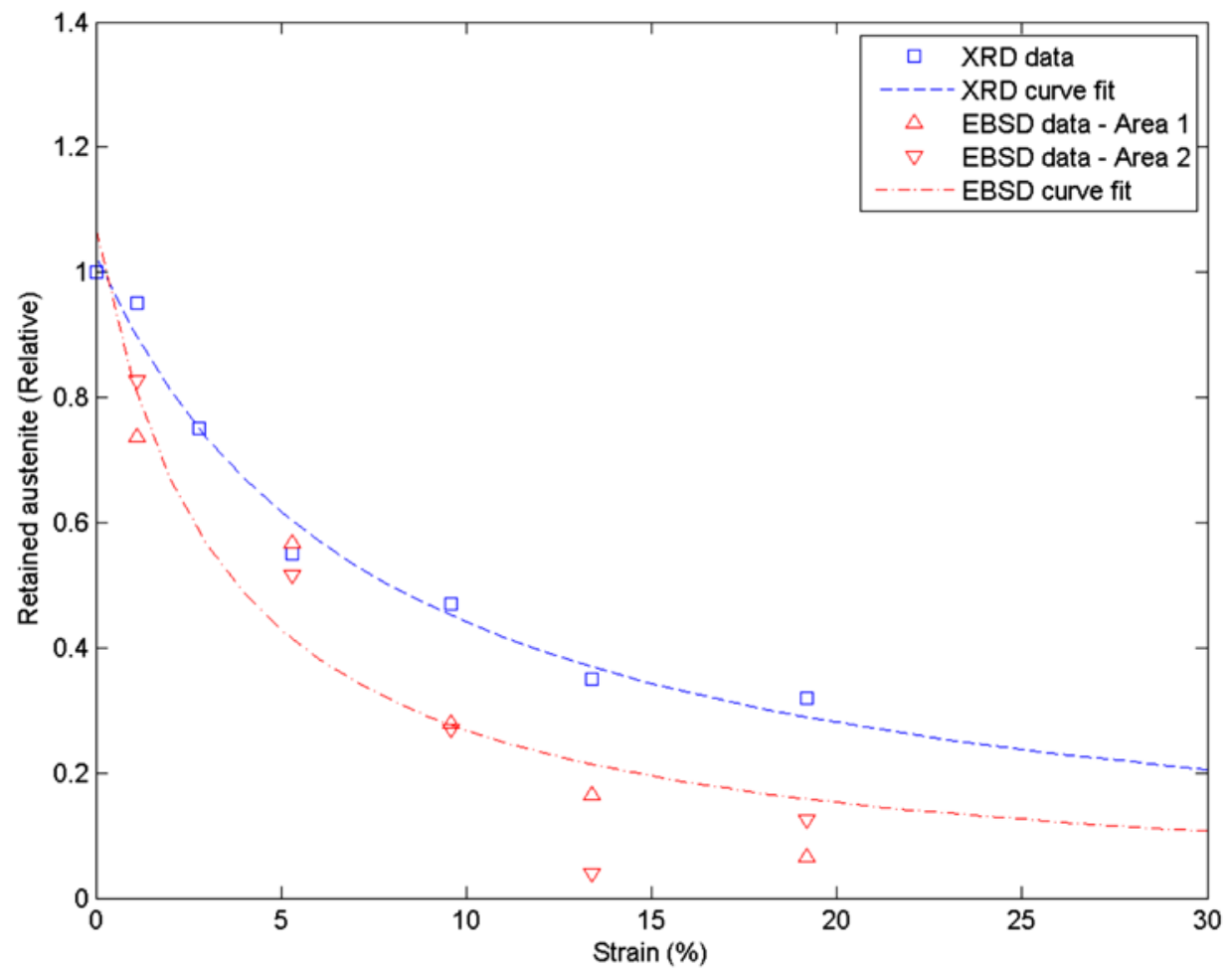

Fig 3: XRD and EBSD analysis of variation of retained austenite content as a function of strain. 
Figure 4

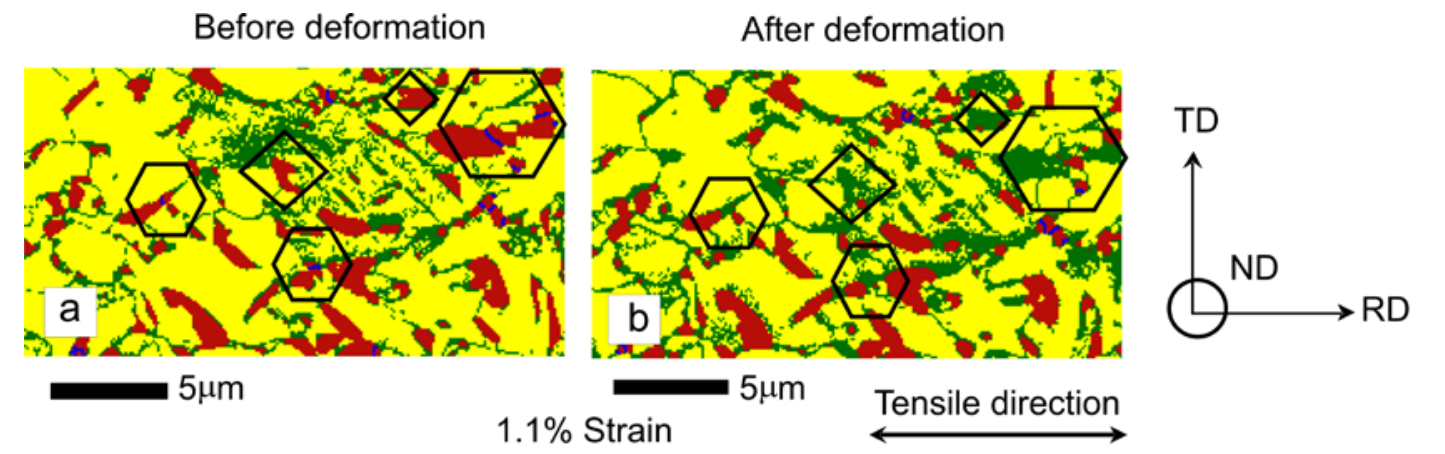

Phase identification map Ferrite $\square$ Austenite

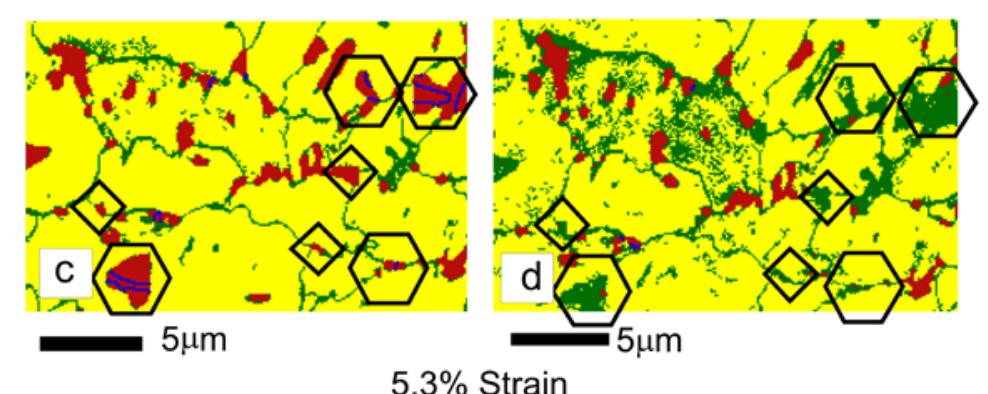

$5.3 \%$ Strain

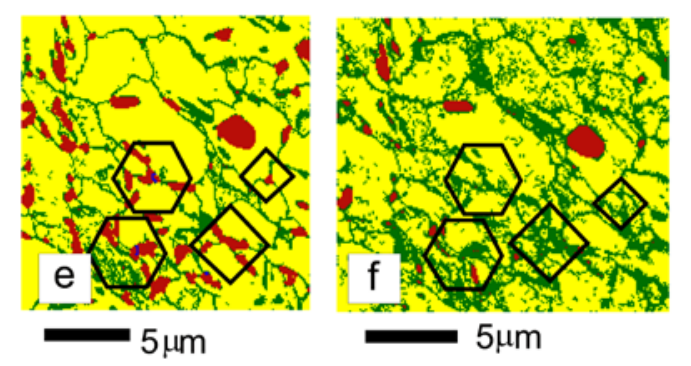

$9.6 \%$ Strain

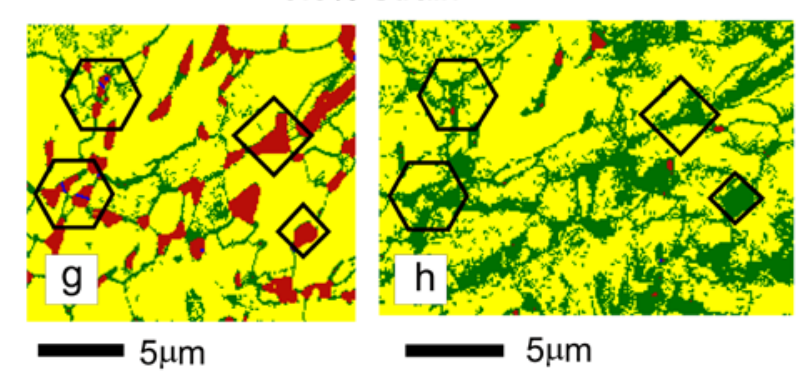

$13.4 \%$ Strain

Fig 4: EBSD phase identification maps showing the transformation of retained austenite grains at ferrite triple junctions and containing twin faults. All the EBSD maps correspond to Area 2 mentioned in Table 3. The squares in the phase identification map indicate transformed austenite grains at the triple junctions of ferrite grains, while the black hexagons indicate austenite grains with twin faults and their twin boundaries are indicated in blue color. 
Figure 5
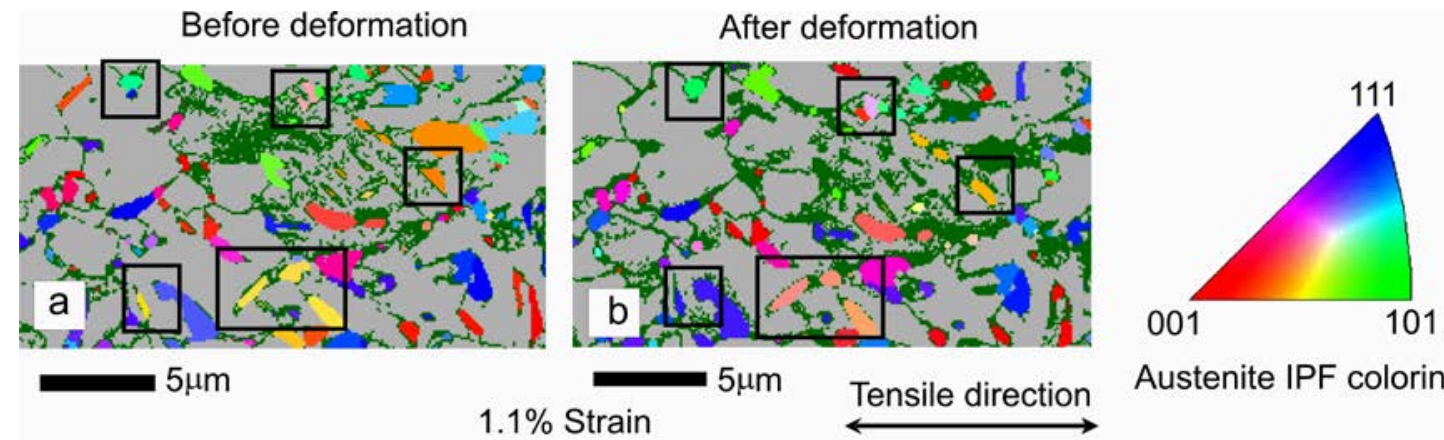

Inverse Pole Figure (IPF) map Ferrite
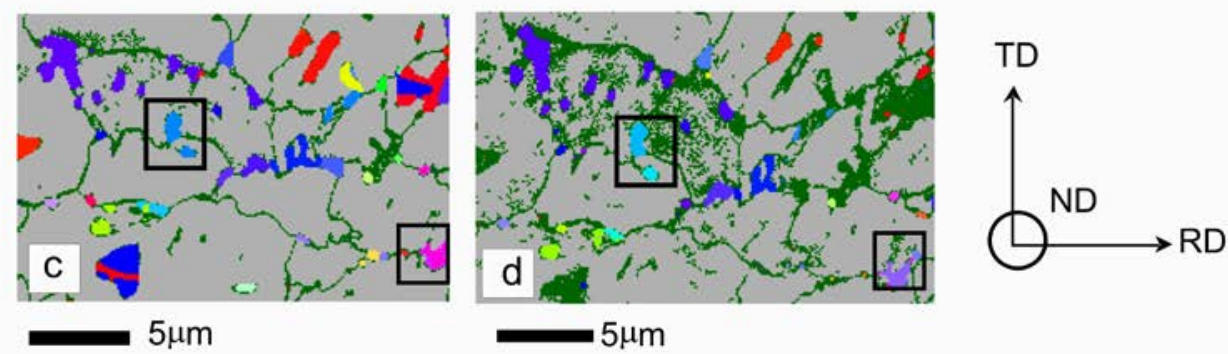

\section{$5.3 \%$ Strain}
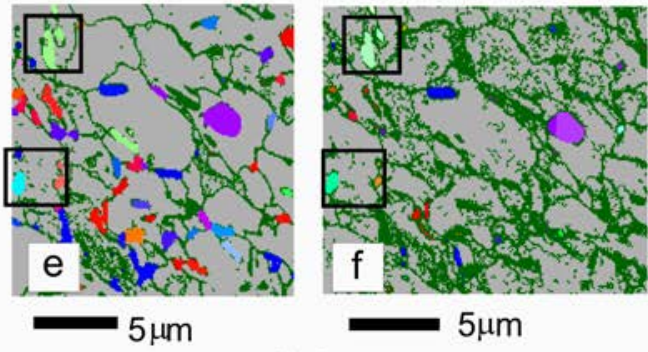

$9.6 \%$ Strain
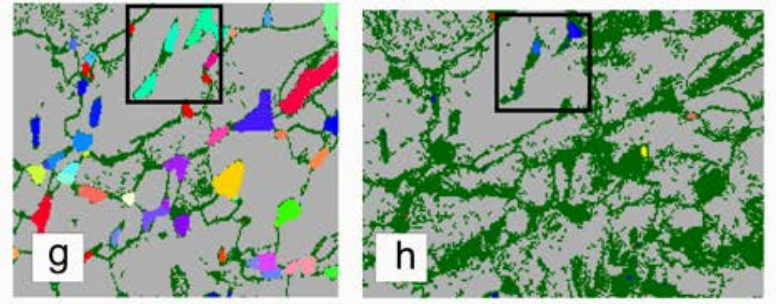

$5 \mu \mathrm{m}$

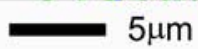

$13.4 \%$ Strain

Fig 5: Inverse Pole Figure maps showing changes in the orientation of embedded austenite grains before and after deformation. The black rectangles in the inverse pole figure map indicate the embedded austenite grains which have rotated during the tensile test. 
Figure 6
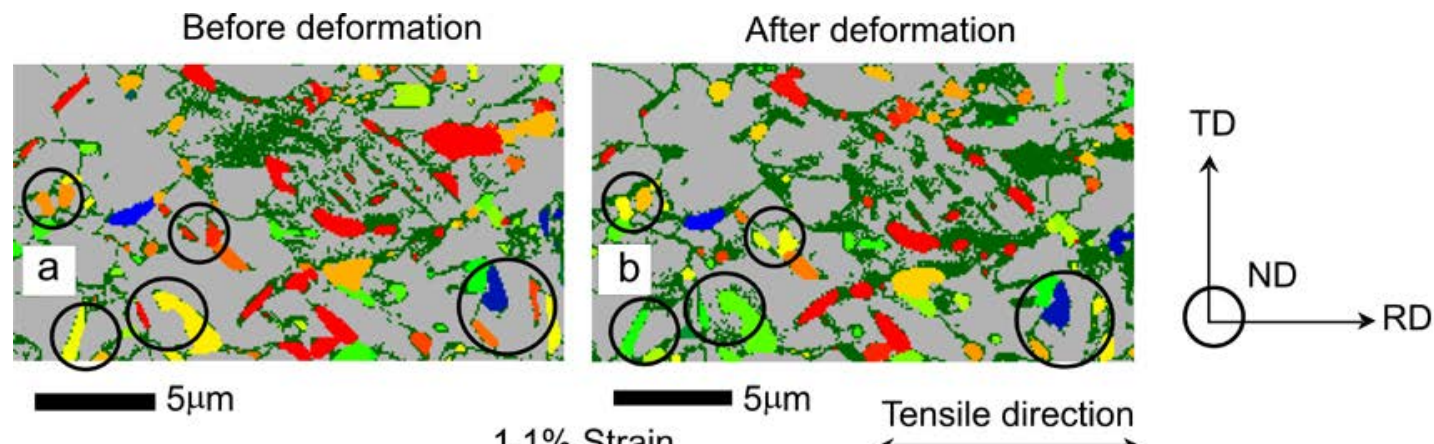

Austenite Schmid factor

$1.1 \%$ Strain

$\stackrel{\longrightarrow}{\longrightarrow}$

Color scale

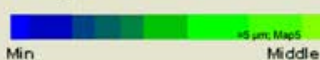

Ferrite

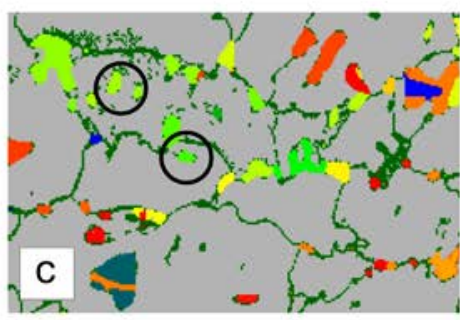

$5 \mu \mathrm{m}$

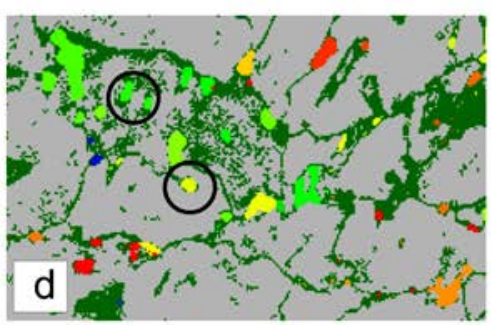

$5 \mu \mathrm{m}$

$5.3 \%$ Strain
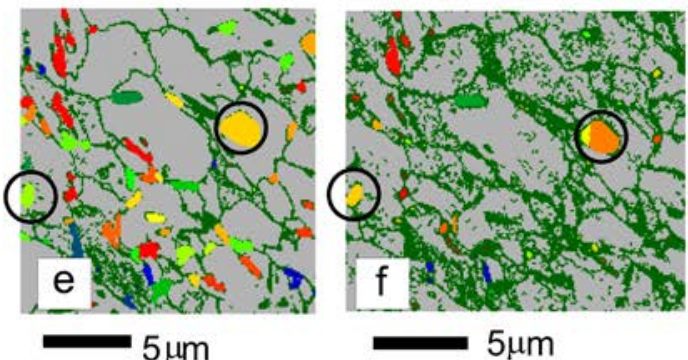

$9.6 \%$ Strain
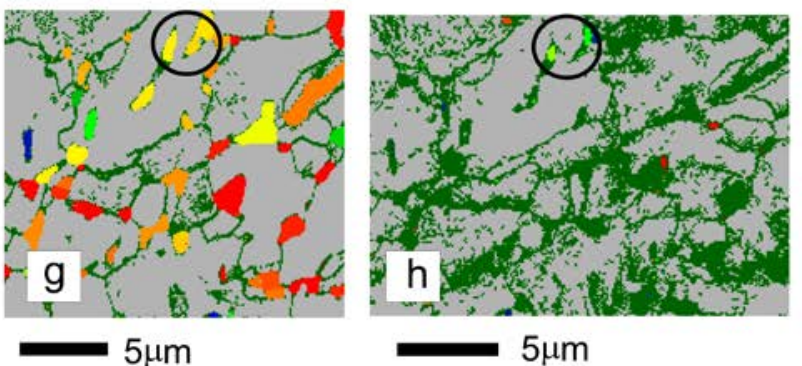

$13.4 \%$ Strain

Fig 6: Schmid factor maps showing changes in the schmid factors of retained austenite grains before and after deformation. The circles indicate the changes in the schmid factors of austenite grains during deformation. 
Figure 7

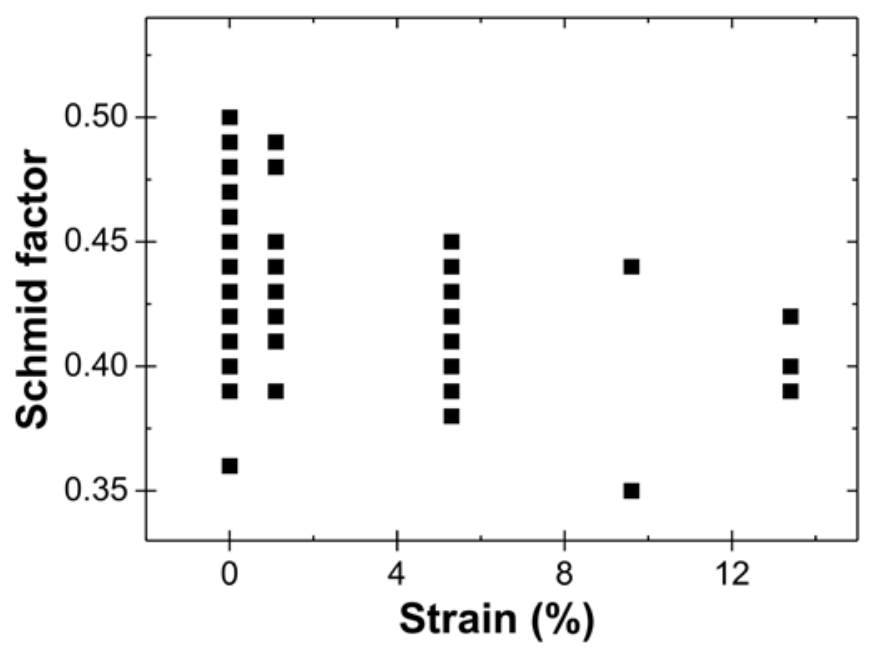

Fig 7: Variation of Schmid factors of embedded austenite grains as a function of strain. 
Figure 8
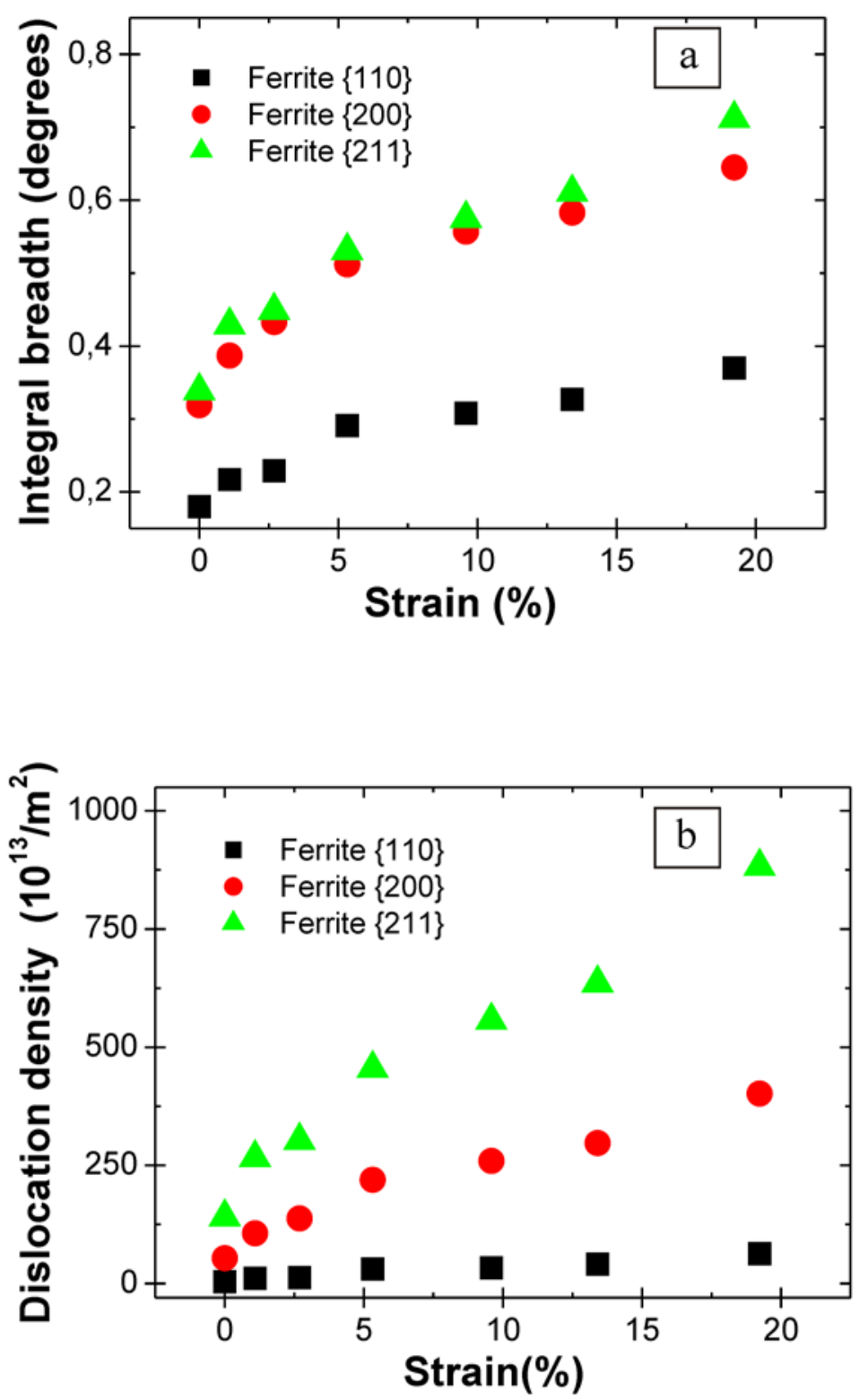

Fig 8: a) Variation of integral breadth of $\{110\},\{200\}$, and $\{211\}$ families of planes in ferrite as function of strain. b) Variation of the dislocation density for $\{110\}$, $\{200\}$, and $\{211\}$ families of planes in ferrite as a function of strain. The integral breadth and the dislocation density were calculated from the XRD data using the formulas mentioned in the experimental Section 2 of the main text. 
- Supporting Information -

\section{Deformation-induced austenite grain rotation and}

\section{transformation in TRIP-assisted steel}

G. K. Tirumalasetty, M.A. van Huis, C. Kwakernaak,

J. Sietsma, W.G Sloof , H.W.Zandbergen

Table S1: Calculated rotation angle $(\theta)$ and axis pairs (r1, r2, r3) for embedded austenite grains and their corresponding ferrite grains.

\begin{tabular}{|c|c|c|c|c|c|c|c|c|c|}
\hline & $\theta\left({ }^{\circ}\right)$ & $\mathrm{r} 1$ & r2 & r3 & Strain & $\theta\left({ }^{\circ}\right)$ & $r 1$ & $\mathrm{r} 2$ & $\mathrm{r} 3$ \\
\hline Figure S2 a & \multicolumn{4}{|c|}{ Austenite grains } & $1.1 \%$ & \multicolumn{4}{|c|}{ Ferrite grains } \\
\hline 1 & 0.6 & -12.3 & -2.4 & -15.6 & & 3.6 & 8 & 1.2 & -9.5 \\
\hline 2 & 3.8 & 8.5 & 1.8 & -10.1 & & 3.8 & 81 & 7.3 & -105.4 \\
\hline 3 & 3.6 & 7.6 & 1.9 & -9.9 & & 3.8 & 81 & 7.3 & -105.4 \\
\hline 4 & 4 & 8.1 & 1.6 & -11.3 & & 3.8 & 8.3 & 1.1 & -10.3 \\
\hline 5 & 3.6 & 8.4 & 1.9 & -9.1 & & 3.8 & 8.3 & 1.1 & -10.3 \\
\hline 6 & 4.2 & 8.7 & 1.3 & -11.9 & & 3.8 & 8.3 & 1.1 & -10.3 \\
\hline 7 & 3.9 & -10.2 & 4 & 16.6 & & 3.9 & 80.6 & 5.2 & -110.8 \\
\hline 8 & 4.7 & 9.1 & 1.2 & -134 & & 3.9 & 80.6 & 5.2 & -110.8 \\
\hline 9 & 3.9 & 85.6 & 7.4 & -104 & & 3.9 & 80.6 & 5.2 & -110.8 \\
\hline 10 & 8.4 & 6.7 & 7.2 & -27.3 & & 3.9 & 80.6 & 5.2 & -110.8 \\
\hline 11 & 9.3 & 5.8 & 8.7 & -30.5 & & 3.9 & 80.6 & 5.2 & -110.8 \\
\hline 12 & 1.5 & -7.8 & -9.7 & 15.5 & & 3.9 & 80.6 & 5.2 & -110.8 \\
\hline 13 & 3.6 & 9.2 & 3.1 & -8.1 & & 4.2 & 87.6 & 2.1 & -115.5 \\
\hline \multicolumn{10}{|l|}{ Figure S1 a } \\
\hline 1 & 3.8 & 80 & 2.8 & -105 & & 4.3 & 88.6 & 9.6 & -120.4 \\
\hline 2 & 8.1 & -3.6 & 11.3 & -15.8 & & 4.3 & 88.6 & 9.6 & -120.4 \\
\hline 3 & 1.5 & -3.1 & 11.5 & -15.9 & & 4.3 & 88.6 & 9.6 & -120.4 \\
\hline 4 & 6.4 & -37.1 & 113.8 & -158.7 & & 4.3 & 88.6 & 9.6 & -120.4 \\
\hline 5 & 3.9 & 7.9 & 1.3 & -10.8 & & 4.3 & 10.1 & 1.9 & -10.9 \\
\hline Figure S2 C & & & & & $5.3 \%$ & & & & \\
\hline 1 & 4.5 & -17 & -156 & -5 & & 4.6 & -6.3 & -75.9 & -142.7 \\
\hline 2 & 0.9 & -4.3 & -8.4 & 13.7 & & 3 & 7.8 & -6.7 & -2.1 \\
\hline 3 & 1.9 & -8 & -52 & -42 & & 1.4 & 2.0 & -1.6 & -4.3 \\
\hline 4 & 2.8 & 1.1 & -91 & -30 & & 1.4 & 2.0 & -1.6 & -4.3 \\
\hline 5 & 3.1 & 3.6 & -9.9 & -1.8 & & 1.4 & 2.0 & -1.6 & -4.3 \\
\hline 6 & 1.5 & 3.9 & -2.3 & -2.8 & & 1.4 & 2.0 & -1.6 & -4.3 \\
\hline 7 & 3.8 & 2.2 & -12.7 & -2.5 & & 1.7 & 2.4 & -3.7 & -3.8 \\
\hline 8 & 0.3 & -4 & -5 & -4 & & 1.7 & 2.4 & -3.7 & -3.8 \\
\hline 9 & 2.8 & 8.8 & -3.1 & -2.9 & & 1.6 & 557 & -7 & 68 \\
\hline 10 & 3.1 & 4.6 & -9.2 & -2.9 & & 2.5 & 7.5 & -2.5 & -3.8 \\
\hline
\end{tabular}




\begin{tabular}{cccccccccc}
\hline Figure S2 e & & & & & $9.6 \%$ & & & \\
1 & 2.8 & 67.9 & 70.9 & 8.7 & & 1.8 & 3.6 & 2.7 & -4.5 \\
2 & 4.8 & 1.3 & -16.5 & -2.1 & & 2.6 & 2.4 & -8.7 & 1.1 \\
3 & 4.8 & 5.9 & 39.6 & -162 & & 3.1 & 6 & -3.3 & -8.4 \\
4 & 0.6 & 7.9 & 10.3 & 15.2 & & 19.4 & -1.9 & 6.8 & 66 \\
Figure S2 $g$ & & & & & $13.4 \%$ & & & & \\
1 & 8.7 & 1.2 & 2 & -1.9 & & 7.9 & 9.2 & 20.4 & -15.9 \\
2 & 14.4 & 1.8 & 3.7 & -2.9 & & 7.9 & 9.2 & 20.4 & -15.9 \\
3 & 9.2 & 5 & 26.1 & -17.9 & & 7.9 & 9.2 & 20.4 & -15.9 \\
\hline
\end{tabular}




\section{Figure S1}
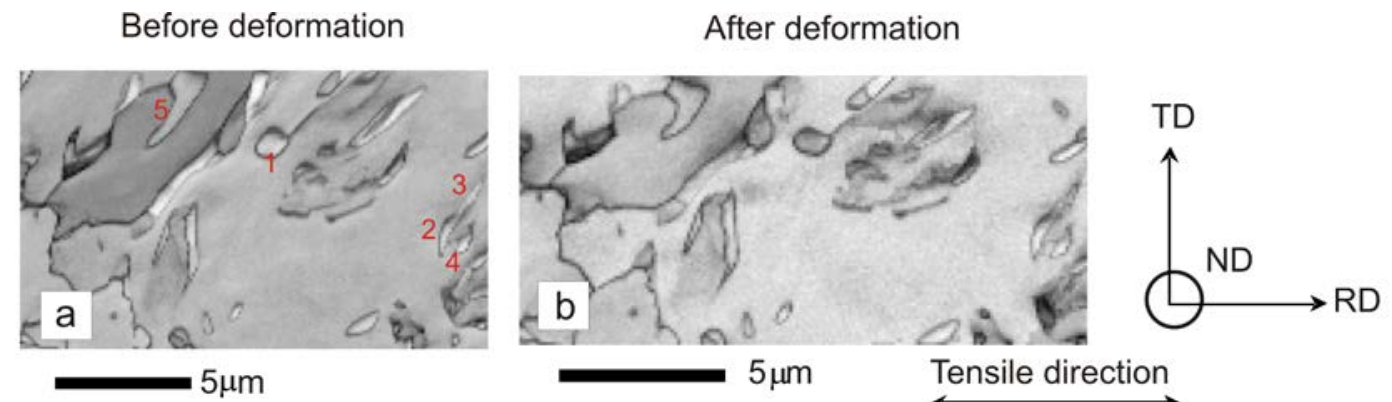

$1.1 \%$ Strain-Area 1

Band contrast map
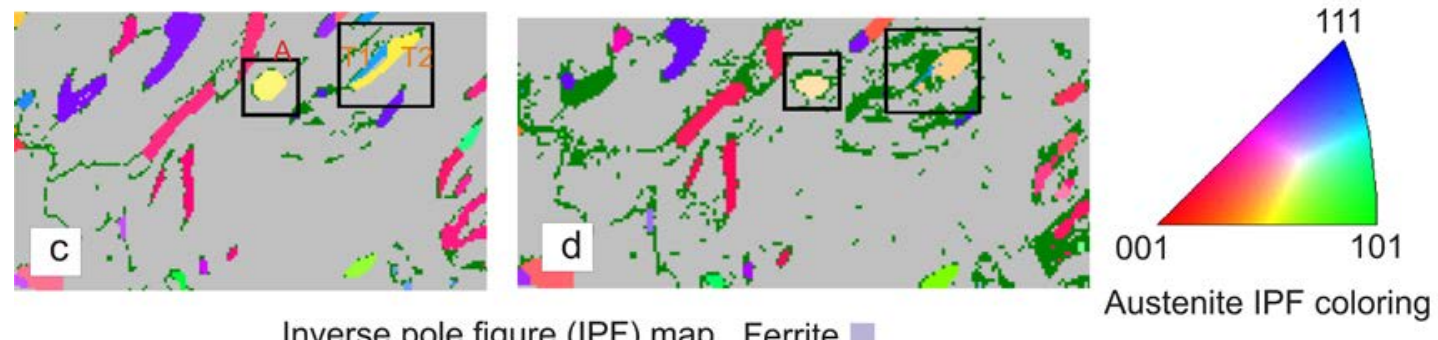

Inverse pole figure (IPF) map Ferrite

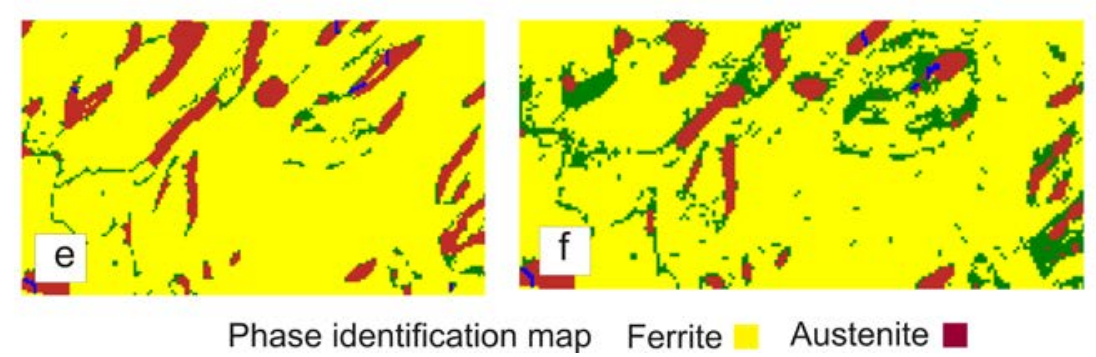

Fig S1: EBSD analysis and variation of retained austenite with 1.1\% strain corresponding to Area 1 in Table 3. 


\section{Figure S2}
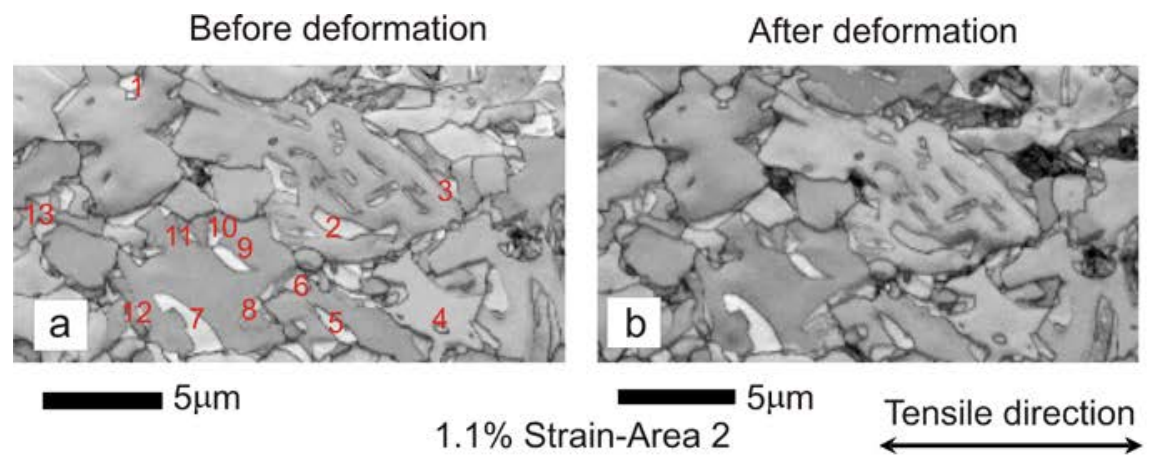

\section{$1.1 \%$ Strain-Area 2 \\ Band contrast map}
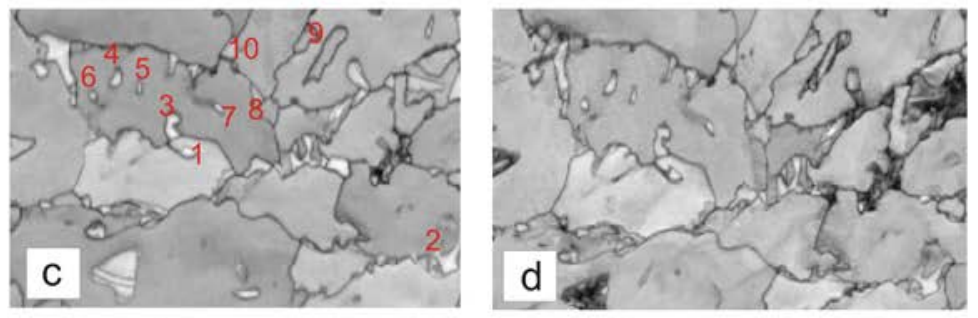

$5 \mu \mathrm{m}$

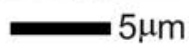

$5.3 \%$ Strain

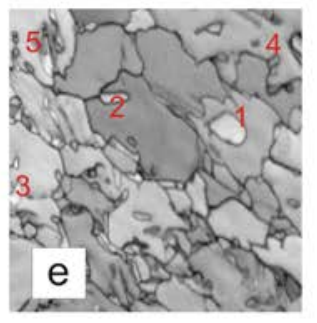

$5 \mu \mathrm{m}$

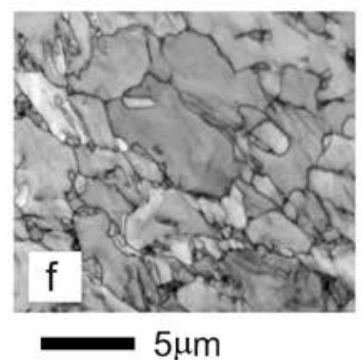

$9.6 \%$ Strain

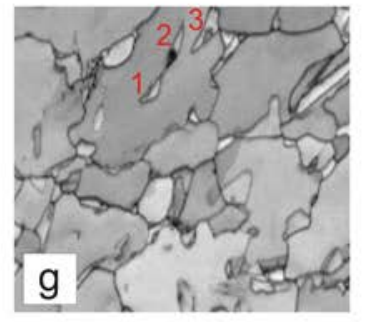

$5 \mu \mathrm{m}$

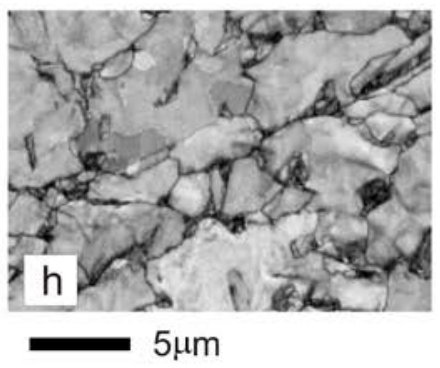

$13.4 \%$ Strain

Fig S2: Band contrast maps showing changes in contrast of embedded austenite grains before and after deformation. The numbers indicated in the band contrast maps 
indicate embedded austenite grains which have rotated during the tensile test and the corresponding rotation angles are mentioned in Table S1.

- Supporting Information -

\section{Deformation-induced austenite grain rotation and}

\section{transformation in TRIP-assisted steel}

G. K. Tirumalasetty, M.A. van Huis, C. Kwakernaak, J. Sietsma, W.G Sloof , H.W.Zandbergen

Table S1: Calculated rotation angle $(\theta)$ and axis pairs (r1, r2, r3) for embedded austenite grains and their corresponding ferrite grains.

\begin{tabular}{|c|c|c|c|c|c|c|c|c|c|}
\hline & $\theta\left({ }^{\circ}\right)$ & $\mathrm{r} 1$ & r2 & r3 & Strain & $\theta\left({ }^{\circ}\right)$ & $\mathrm{r} 1$ & r2 & r3 \\
\hline Figure S2 a & \multicolumn{4}{|c|}{ Austenite grains } & $1.1 \%$ & \multicolumn{4}{|c|}{ Ferrite grains } \\
\hline 1 & 0.6 & -12.3 & -2.4 & -15.6 & & 3.6 & 8 & 1.2 & -9.5 \\
\hline 2 & 3.8 & 8.5 & 1.8 & -10.1 & & 3.8 & 81 & 7.3 & -105.4 \\
\hline 3 & 3.6 & 7.6 & 1.9 & -9.9 & & 3.8 & 81 & 7.3 & -105.4 \\
\hline 4 & 4 & 8.1 & 1.6 & -11.3 & & 3.8 & 8.3 & 1.1 & -10.3 \\
\hline 5 & 3.6 & 8.4 & 1.9 & -9.1 & & 3.8 & 8.3 & 1.1 & -10.3 \\
\hline 6 & 4.2 & 8.7 & 1.3 & -11.9 & & 3.8 & 8.3 & 1.1 & -10.3 \\
\hline 7 & 3.9 & -10.2 & 4 & 16.6 & & 3.9 & 80.6 & 5.2 & -110.8 \\
\hline 8 & 4.7 & 9.1 & 1.2 & -134 & & 3.9 & 80.6 & 5.2 & -110.8 \\
\hline 9 & 3.9 & 85.6 & 7.4 & -104 & & 3.9 & 80.6 & 5.2 & -110.8 \\
\hline 10 & 8.4 & 6.7 & 7.2 & -27.3 & & 3.9 & 80.6 & 5.2 & -110.8 \\
\hline 11 & 9.3 & 5.8 & 8.7 & -30.5 & & 3.9 & 80.6 & 5.2 & -110.8 \\
\hline 12 & 1.5 & -7.8 & -9.7 & 15.5 & & 3.9 & 80.6 & 5.2 & -110.8 \\
\hline 13 & 3.6 & 9.2 & 3.1 & -8.1 & & 4.2 & 87.6 & 2.1 & -115.5 \\
\hline \multicolumn{10}{|l|}{ Figure S1 a } \\
\hline 1 & 3.8 & 80 & 2.8 & -105 & & 4.3 & 88.6 & 9.6 & -120.4 \\
\hline 2 & 8.1 & -3.6 & 11.3 & -15.8 & & 4.3 & 88.6 & 9.6 & -120.4 \\
\hline 3 & 1.5 & -3.1 & 11.5 & -15.9 & & 4.3 & 88.6 & 9.6 & -120.4 \\
\hline 4 & 6.4 & -37.1 & 113.8 & -158.7 & & 4.3 & 88.6 & 9.6 & -120.4 \\
\hline 5 & 3.9 & 7.9 & 1.3 & -10.8 & & 4.3 & 10.1 & 1.9 & -10.9 \\
\hline Figure S2 c & & & & & $5.3 \%$ & & & & \\
\hline 1 & 4.5 & -17 & -156 & -5 & & 4.6 & -6.3 & -75.9 & -142.7 \\
\hline 2 & 0.9 & -4.3 & -8.4 & 13.7 & & 3 & 7.8 & -6.7 & -2.1 \\
\hline 3 & 1.9 & -8 & -52 & -42 & & 1.4 & 2.0 & -1.6 & -4.3 \\
\hline 4 & 2.8 & 1.1 & -91 & -30 & & 1.4 & 2.0 & -1.6 & -4.3 \\
\hline 5 & 3.1 & 3.6 & -9.9 & -1.8 & & 1.4 & 2.0 & -1.6 & -4.3 \\
\hline 6 & 1.5 & 3.9 & -2.3 & -2.8 & & 1.4 & 2.0 & -1.6 & -4.3 \\
\hline 7 & 3.8 & 2.2 & -12.7 & -2.5 & & 1.7 & 2.4 & -3.7 & -3.8 \\
\hline
\end{tabular}




\begin{tabular}{|c|c|c|c|c|c|c|c|c|c|}
\hline 8 & 0.3 & -4 & -5 & -4 & & 1.7 & 2.4 & -3.7 & -3.8 \\
\hline 9 & 2.8 & 8.8 & -3.1 & -2.9 & & 1.6 & 557 & -7 & 68 \\
\hline 10 & 3.1 & 4.6 & -9.2 & -2.9 & & 2.5 & 7.5 & -2.5 & -3.8 \\
\hline Figure S2 e & & & & & $9.6 \%$ & & & & \\
\hline 1 & 2.8 & 67.9 & 70.9 & 8.7 & & 1.8 & 3.6 & 2.7 & -4.5 \\
\hline 2 & 4.8 & 1.3 & -16.5 & -2.1 & & 2.6 & 2.4 & -8.7 & 1.1 \\
\hline 3 & 4.8 & 5.9 & 39.6 & -162 & & 3.1 & 6 & -3.3 & -8.4 \\
\hline 4 & 0.6 & 7.9 & 10.3 & 15.2 & & 19.4 & -1.9 & 6.8 & 66 \\
\hline Figure $S 2 g$ & & & & & $13.4 \%$ & & & & \\
\hline 1 & 8.7 & 1.2 & 2 & -1.9 & & 7.9 & 9.2 & 20.4 & -15.9 \\
\hline 2 & 14.4 & 1.8 & 3.7 & -2.9 & & 7.9 & 9.2 & 20.4 & -15.9 \\
\hline 3 & 9.2 & 5 & 26.1 & -17.9 & & 7.9 & 9.2 & 20.4 & -15.9 \\
\hline
\end{tabular}




\section{Figure S1}
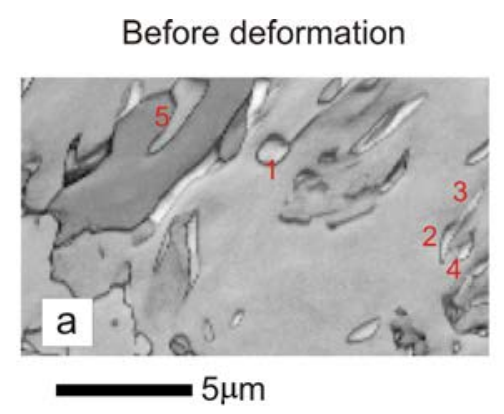

$5 \mu \mathrm{m}$

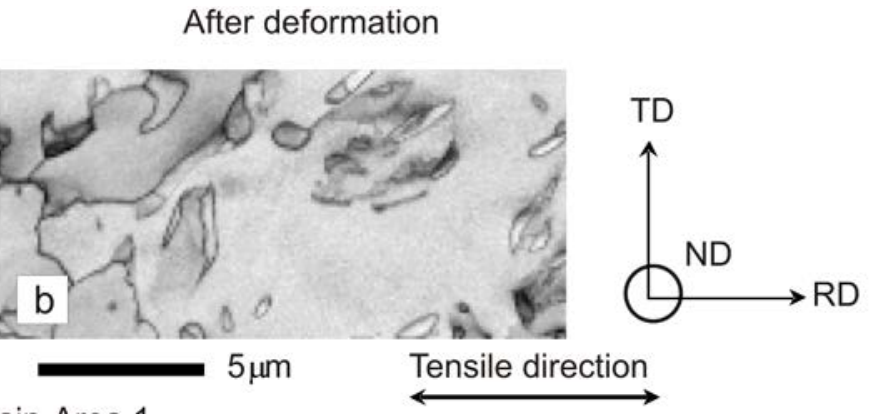

$1.1 \%$ Strain-Area 1

Band contrast map
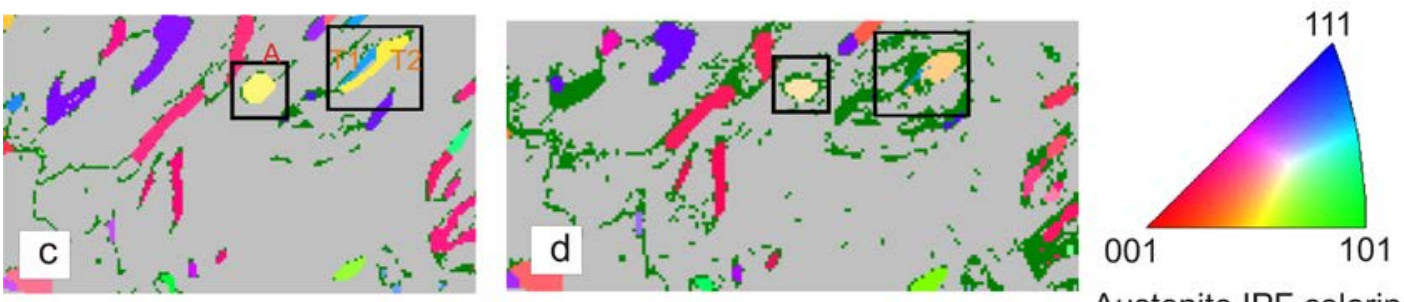

Inverse pole figure (IPF) map Ferrite

Austenite IPF coloring
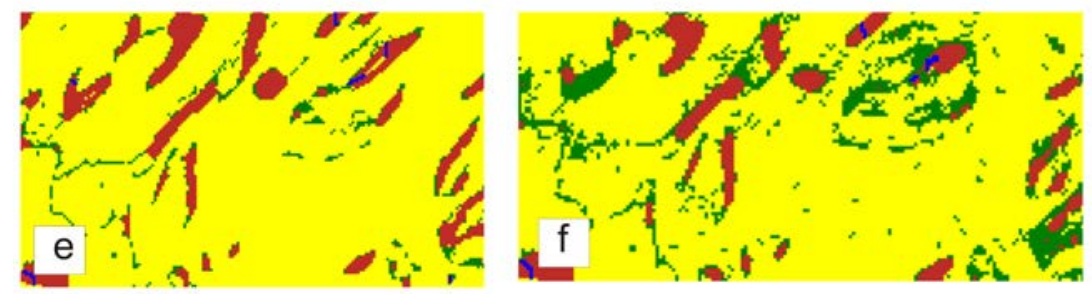

Phase identification map Ferrite Austenite

Fig S1: EBSD analysis and variation of retained austenite with 1.1\% strain corresponding to Area 1 in Table 3. 


\section{Figure S2}
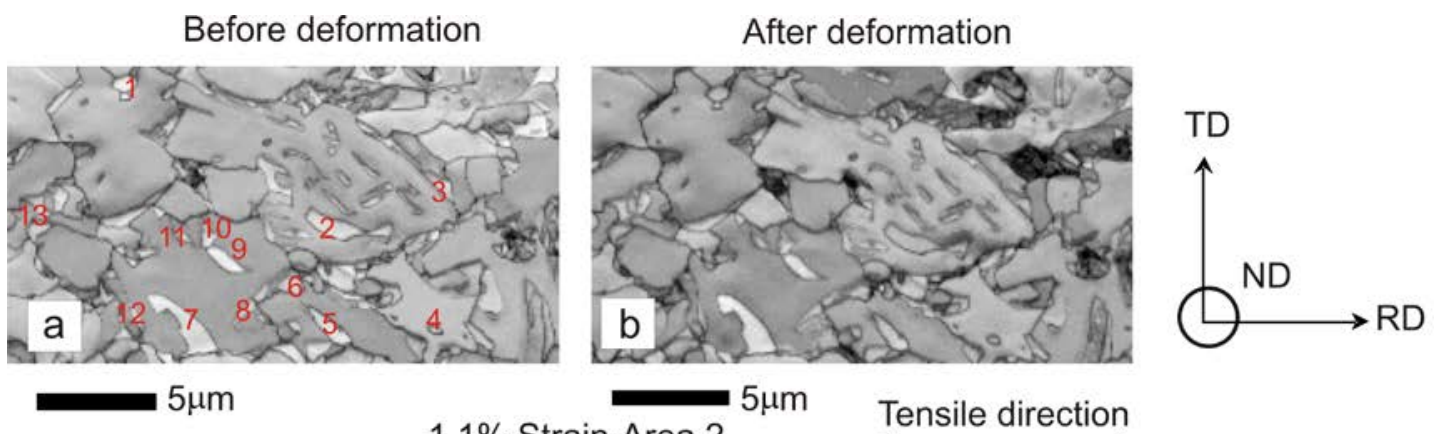

$5 \mu \mathrm{m}$

\section{$1.1 \%$ Strain-Area 2}

Band contrast map
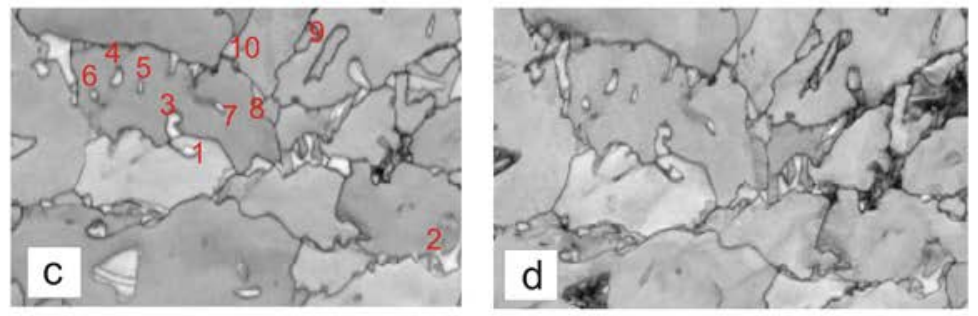

$5 \mu \mathrm{m}$

$-5 \mu \mathrm{m}$

$5.3 \%$ Strain

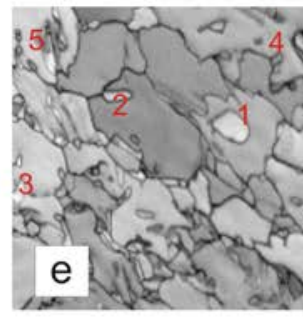

$5 \mu \mathrm{m}$

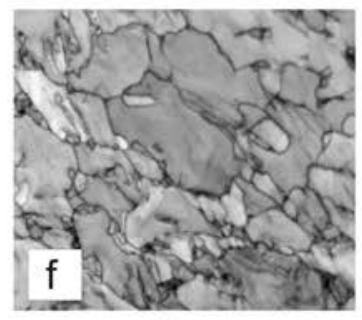

$5 \mu \mathrm{m}$

9.6\% Strain
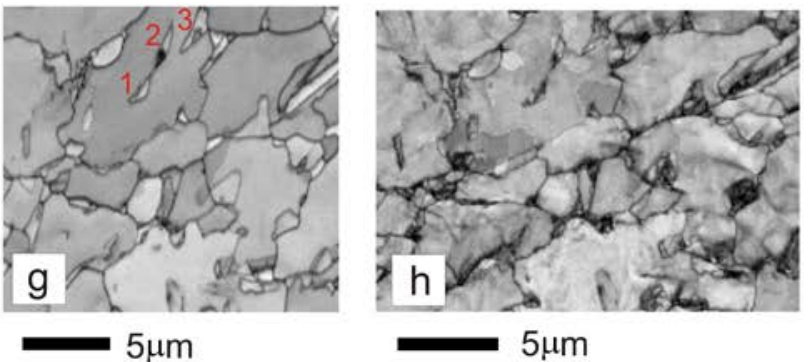

$13.4 \%$ Strain

Fig S2: Band contrast maps showing changes in contrast of embedded austenite grains before and after deformation. The numbers indicated in the band contrast maps 
indicate embedded austenite grains which have rotated during the tensile test and the corresponding rotation angles are mentioned in Table S1. 